\title{
Secondhand smoke exposure, diabetes, and high BMI are risk factors for uterine cervical cancer: a cross-sectional study from the Korea national health and nutrition examination survey (2010-2018)
}

\author{
Ji Young Kim, Dae Woo Lee, Min Jeong Kim, Jae Eun Shin, Yeun Joo Shin and Hae Nam Lee*
}

\begin{abstract}
Background: Human papilloma virus infection and tobacco smoking are the major risk factors for cervical cancer. There are limited studies searching other risk factors for cervical cancer and the results are not consistent. This study investigated the relations between cervical cancer and possible risk factors, including secondhand cigarette smoke exposure, diabetes, body mass index (BMI), and work schedule.

Methods: In this cross-sectional study, 29,557 women completed a cervical cancer questionnaire and were selected using 2010-2018 data from the Korea National Health and Nutrition Examination Survey. Details in secondhand smoke exposure, diabetes, BMI, and work schedule were assessed with participants' health interviews and healthrelated surveys.

Results: Two hundred sixty-two women (0.89\%) in the sample were diagnosed with cervical cancer. Domestic secondhand smoke exposure, diabetes, and high BMI significantly increased cervical cancer risk. Respective odds ratios and 95\% confidence intervals were: 1.547 (1.042-2.297), 2.156 (1.535-3.027), and 1.036 (1.006-1.067). Weekly work hours, and work schedule were not significantly related to cervical cancer incidence.
\end{abstract}

Conclusion: Among Korean women, passive exposure to cigarette smoke at home, diabetes, and high BMI increase risk for cervical cancer.

Keywords: KNHANES (Korea National Health and nutrition examination survey), Cervical cancer, Diabetes, BMI, Secondhand cigarette smoke

\section{Background}

Cervical cancer is the fourth most common and the third most lethal female malignancy worldwide [1]. Cervical cancer is caused by human papilloma virus (HPV) infection, which is one of the most powerful human carcinogens and

\footnotetext{
* Correspondence: leehn@catholic.ac.kr

Department of Obstetrics and Gynecology, Bucheon St, Mary's Hospital, College of Medicine, The Catholic University of Korea, 327, Sosa-ro, Bucheon-si, Gyeonggi-do, 14647 Seoul, Republic of Korea
}

has been implicated in several cancers, including uterine cervix, anorectum and oropharynx [2]. In addition to HPV infection, young age at first intercourse, multiple sexual partners, cigarette smoking, race, high parity, low socioeconomic status, and chronic immune suppression are also risk factors for cervical cancer [3].

Tobacco smoking is a strong risk factor for cervical neoplasia. Smoking status, duration, and intensity are associated with twofold increase in risk for high-grade

(c) The Author(s). 2021 Open Access This article is licensed under a Creative Commons Attribution 4.0 International License, which permits use, sharing, adaptation, distribution and reproduction in any medium or format, as long as you give appropriate credit to the original author(s) and the source, provide a link to the Creative Commons licence, and indicate if changes were made. The images or other third party material in this article are included in the article's Creative Commons licence, unless indicated otherwise in a credit line to the material. If material is not included in the article's Creative Commons licence and your intended use is not permitted by statutory regulation or exceeds the permitted use, you will need to obtain permission directly from the copyright holder. To view a copy of this licence, visit http://creativecommons.org/licenses/by/4.0/ The Creative Commons Public Domain Dedication waiver (http://creativecommons.org/publicdomain/zero/1.0/) applies to the data made available in this article, unless otherwise stated in a credit line to the data. 
cervical dysplasia and invasive carcinoma, independent of HPV infection [4]. Passive cigarette smoking, or secondhand smoke exposure is also considered a risk factor for cervical carcinogenesis, although related study results have been inconsistent. Su et al. reported a 1.7fold increase in cervical cancer risk among those exposed to secondhand smoke, whereas Louie et al. concluded that passive smoking is not an independent risk factor for invasive cervical cancer in the absence of active smoking $[5,6]$.

Diabetes mellitus (DM), especially type 2 diabetes, is a major risk factor for many cancers. The association between endometrial cancer and diabetes is wellestablished, and some have shown weak correlations between ovarian cancer and diabetes [7, 8]. However, the relationship between cervical cancer incidence and type 2 diabetes remains unclear and relevant studies have been limited.

Increased body mass index (BMI) has been considered to increase the risk of many cancers. One meta-analysis reported that each $5 \mathrm{~kg}$ increase in adult weight gain raises the risk of post-menopausal breast (11\%), endometrial (39\%) and ovarian cancer (13\%) [9]. A longitudinal study from the United States suggested that a longer duration of overweight and obesity is associated with an increased risk of developing several forms of cancer, such as breast, colon, endometrial, and kidney cancer [10]. Not many studies are there for the association between obesity and cervical cancer.

Socioeconomic disparities among women also affect cervical cancer occurrence. Cervical cancer incidence and mortality are much higher in low- and middleincome countries compared with high-income countries [11]. In Korea, women with lower education levels and lower household income have significantly lower cervical cancer screening rates than do highly educated and high-earning females $[12,13]$. Regarding occupation, service and sales workers appear to have a higher risk of cervical cancer compared with those in other fields [14].. To our knowledge, the relationship between work schedule and cervical neoplasm has not been addressed.

To better prevent cervical cancer, and raise public health awareness, risk factors other than HPV infection and smoking must be identified. Thus, the study purpose was to determine the relationships between cervical cancer and potential risk factors, including passive cigarette smoking, diabetes-related factors and work schedule, using data from the Korea National Health and Nutrition Examination Survey (KNHANES).

\section{Methods}

The analyses presented herein are based on data collected during the 2010-2018 KNHANES, which began in 1998 and is administered by the Division of Health and Nutrition Survey under the Korea Disease Control and Prevention Agency. KNHANES is an ongoing population-based cross-sectional survey designed to assess the health and nutritional status of Koreans. The study monitors trends in health risk factors, assesses the prevalence of major chronic diseases, and provides data for the development and evaluation of health policies and programs in Korea [15].

The health interviews and examinations were conducted in mobile examination centers, while the nutritional surveys were performed by trained physicians or nurses who visited each household. Participants were asked to complete the cervical cancer, diabetes, smoking, and working conditions questionnaire during their health interviews. Written informed consent was acquired from all participants before the survey was administered. Institutional Review Board of the Catholic University of Korea, Bucheon, Republic of Korea approved this study (HC20ZASI0107).

During the 2010-2018 KNHANES, 32,485 women aged 18 years or older participated. The annual participant distribution is shown in Table 1. Among the 29,557 women who completed the cervical cancer questionnaire, $262(0.89 \%)$ were diagnosed with cervical cancer. Among the sample with cervical cancer, there were 45 women with diabetes, who were classified into three groups according to treatment method: insulin injection, medication, or nonpharmacological treatment. Participants who reported secondhand smoke exposure were asked to identify whether this occurred in their workplace, home, or public places. Work schedule was categorized as: day shift, evening shift, night shift, regular 12-h shift, 24-h shift, split shift, irregular shift, or other. Having cervical cancer or diabetes at the health interview was defined based on a diagnosis by a qualified physician.

Statistical analyses conducted using Stata (v. 16.1; StataCorp LLC, College Station, TX, USA), reflect the complex sampling design and sampling weights of the KNHANES, and were chosen to provide nationally representative prevalence estimates. Fisher's exact probability tests were performed to identify distribution patterns by cervical cancer occurrence and odds ratios (OR), along with $95 \%$ confidence intervals (CI), were calculated using logistic regression models with respective independent variables. Adjusted ORs with 95\% CIs were calculated using multiple logistic regression analysis, including variables that were statistically significant on univariate analysis. To compare mean BMI and weekly work hours, independent samples t-tests were applied.

\section{Results}

Distribution patterns by categories are shown in Table 2 . To investigate the relations between passive smoke 
Table 1 Sample distribution by study year

\begin{tabular}{llll}
\hline Year & $\begin{array}{l}\text { Without cervical } \\
\text { cancer }(\mathbf{n})\end{array}$ & $\begin{array}{l}\text { Cervical cancer } \\
(\mathbf{n})\end{array}$ & $\begin{array}{l}\text { Cervical cancer } \\
(\mathbf{\%})\end{array}$ \\
\hline 2010 & 3555 & 30 & 0.84 \\
2011 & 3478 & 23 & 0.66 \\
2012 & 3313 & 16 & 0.48 \\
2013 & 3103 & 33 & 1.06 \\
2014 & 2942 & 31 & 1.05 \\
2015 & 2921 & 27 & 0.92 \\
2016 & 3337 & 38 & 1.14 \\
2017 & 3252 & 36 & 1.11 \\
2018 & 3394 & 28 & 0.82 \\
total & 29,295 & 262 & 0.89 \\
\hline
\end{tabular}

exposure and cervical cancer occurrence, secondhand smoke in the workplace, home, and public places were analyzed separately. Passive smoke exposure at work was negatively related to cervical cancer risk. Incidence of cervical cancer among women exposed to secondhand smoking at work was $0.57 \%$, whereas $0.95 \%$ of unexposed women had cervical cancer $(\chi 2=6.835, p=0.009)$.
Domestic passive smoke exposure was related with increased cervical cancer incidence. Cervical cancer was present among $1.26 \%$ of women exposed domestic secondhand smoke, but only $0.85 \%$ of those living in a smoke-free home $(\chi 2=4.017, p=0.045)$. Among women exposed to secondhand smoke in public places, $0.84 \%$ had cervical cancer, which did not differ significantly from the rate of $1.01 \%$ among those who were unexposed $(\chi 2=0.569, p>0.05)$.

Using pooled data, cervical cancer prevalence among women with diabetes was $1.89 \%$, significantly higher than $0.80 \%$ among women without diabetes $(\chi 2=29.712, p<0.001)$. However, insulin usage for diabetes treatment was not significantly related to cervical cancer occurrence $(\chi 2=2.369, p>0.05)$. Nonpharmacologic DM treatment $(\chi 2=4.026, p=0.045)$ and medication prescribed for diabetes $(\chi 2=33.610, p<0.001)$ were significantly related to cervical cancer. Mean BMI among those with cervical cancer $(24.22 \pm 3.53)$ was substantially higher than among those without cervical cancer $(23.47 \pm 3.58$; $t=-3.403, p=0.001)$.

Mean weekly work hours among women with cervical cancer $(34.74 \pm 16.69)$ did not differ significantly from

Table 2 Sample distribution by passive smoking, diabetes, DM treatments, and work schedule

\begin{tabular}{|c|c|c|c|c|c|}
\hline Variables & & & $\mathrm{n}$ & Cervical cancer (\%) & $p^{*}$ \\
\hline \multirow[t]{6}{*}{ Passive smoking } & Workplace & Unexposed & 24,044 & $228(0.95)$ & 0.009 \\
\hline & & Exposed & 5081 & $29(0.57)$ & \\
\hline & Domestic & Unexposed & 27,142 & $230(0.85)$ & 0.045 \\
\hline & & Exposed & 2222 & $28(1.26)$ & \\
\hline & Public place & Unexposed & 10,680 & $108(1.01)$ & 0.451 \\
\hline & & Exposed & 2264 & $19(0.84)$ & \\
\hline \multirow[t]{2}{*}{ Diabetes } & & Nondiabetic & 27,175 & $217(0.80)$ & 0.000 \\
\hline & & Diabetic & 2380 & $45(1.89)$ & \\
\hline \multirow[t]{6}{*}{ DM treatment } & Insulin injection. & No & 29,340 & $258(0.88)$ & 0.124 \\
\hline & & Yes & 214 & $4(1.87)$ & \\
\hline & Medication & No & 27,427 & $219(0.80)$ & 0.000 \\
\hline & & Yes & 2127 & $43(2.02)$ & \\
\hline & Nonpharmacologic & No & 29,247 & $256(0.88)$ & 0.045 \\
\hline & & Yes & 307 & $6(1.95)$ & \\
\hline \multirow[t]{8}{*}{ Work schedule } & & Day shift & 13,973 & $100(0.72)$ & 0.354 \\
\hline & & Evening shift & 2102 & $16(0.76)$ & \\
\hline & & Night shift & 278 & $0(0.00)$ & \\
\hline & & 12-h regular shift & 297 & $0(0.00)$ & 0.438 \\
\hline & & 24-h regular shift & 43 & $0(0.00)$ & \\
\hline & & Split shift & 133 & $1(0.75)$ & \\
\hline & & Irregular shift & 93 & $1(1.08)$ & \\
\hline & & Other & 64 & $0(0.00)$ & \\
\hline
\end{tabular}


women without cervical cancer $(37.21 \pm 18.35 ; \mathrm{t}=1.460$, $p>0.05)$. Nor were there difference between those working the day, evening, or night shifts $\left(x^{2}=2.074, p>0.05\right)$ or between those working regular 12-h, 24-h, split, irregular, or another shift type $\left(x^{2}=3.767, p>0.05\right)$.

The relationships between cervical cancer and passive smoking, diabetes, BMI, weekly work hours, and work schedule are shown in Table 3. The OR for cervical cancer based on exposure to secondhand smoke at home was 1.488 (95\% CI: 1.002-2.207, $p=$ 0.049). For exposure to secondhand smoke in the workplace, the OR for cervical cancer was 0.595 (95\% CI: $0.404-0.876, p=0.009$ ). In multiple logistic regression analysis after adjusting for other parameters which were statistically significant in the univariate analysis, the OR for cervical cancer with domestic secondhand smoke exposure was 1.547 (95\% CI: $1.042-2.297, p=0.03$ ). For exposure to workplace secondhand smoke, the adjusted OR was 0.603 (95\% CI: $0.408-0.891, p=0.011$ ).

The relation between diabetes and cervical cancer was significant (OR: 2.369, 95\% CI: 1.713-3.274, $p<$ 0.001). After adjusting for other variables, diabetes still showed a statistically significant association with cervical cancer (adjusted OR: 2.156, 95\% CI: 1.5353.027, $p<0.001)$.

BMI level (OR: 1.056, 95\% CI: 1.026-1.086, $p<0.001$ ) was positively related to cervical cancer incidence. In multivariate analysis BMI still showed significant association with cervical cancer (Adjusted OR: 1.036, 95\% CI: $1.006-1.067, p=0.020$ ).

Regarding weekly work hours and work schedule, insulin usage and non-pharmacological method for DM treatment, there were fewer than expected participants in many cells, which thus failed to meet the analysis criteria. Consequently, the omnibus analyses for these factors were not statistically significant.

\section{Discussion}

This study investigated whether secondhand smoke exposure, diabetes, BMI, or work schedule are risk factors for cervical carcinogenesis.

The role of passive cigarette smoking in cervical neoplasia is controversial. Herein, secondhand smoke exposure at home was significantly related to cervical cancer. This finding is consistent with most studies, which have shown that secondhand smoke exposure is positively correlated with cervical cancer [5, 16-18]. Some studies have also reported passive smoking as an independent risk factor for abnormal cervical cytology or cervical intraepithelial neoplasm (CIN) [19-21]. However, most reports did not adjust for covariates like dose of tobacco exposure, sexual behavior, socioeconomic conditions, and (especially important) HPV infection status. A few investigators have proposed that passive smoking is statistically unrelated to CIN or cervical cancer after accounting for HPV infection status [6, 22, 23]. Interestingly, we identified that workplace secondhand smoke exposure is associated with lower cervical cancer risk. Considering the KNHANES data characteristics, it is possible that women diagnosed with cervical cancer may seek out smoke-free work environment and move to such jobs.

There was a substantial association between diabetes and cervical cancer. Several studies have reported increased risk for and mortality from many cancer types among patients with diabetes, especially type 2 DM $[7,8,24-26]$. Some characteristics of diabetes may explain this carcinogenic tendency, including hyperinsulinemia, hyperglycemia, and chronic inflammatory status. These conditions all encourage cellular proliferative, angiogenetic, antiapoptotic, and metastatic activities [7, 27]. After adjusting for other variables, the association between diabetes and cervical cancer was still markedly increased and

Table 3 Relations between risk factors and cervical cancer

\begin{tabular}{|c|c|c|c|c|c|}
\hline & & \multicolumn{2}{|l|}{ Univariate } & \multicolumn{2}{|l|}{ Multivariate } \\
\hline & & $\mathrm{OR}^{\mathrm{a}}(95 \% \mathrm{Cl})$ & $p$ & Adjusted $\mathrm{OR}^{\mathrm{b}}(95 \% \mathrm{Cl})$ & $p$ \\
\hline \multirow[t]{3}{*}{ Passive smoking } & Work place & $0.595(0.404-0.876)$ & 0.009 & $0.603(0.408-0.891)$ & 0.011 \\
\hline & Domestic & $1.488(1.002-2.207)$ & 0.049 & $1.547(1.042-2.297)$ & 0.030 \\
\hline & Public place & $0.836(0.513-1.365)$ & 0.475 & & \\
\hline Diabetes & & 2.369 (1.713-3.274) & 0.000 & $2.156(1.535-3.027)$ & 0.000 \\
\hline BMl & & $1.056(1.026-1.086)$ & 0.000 & $1.036(1.006-1.067)$ & 0.020 \\
\hline Weekly work hours & & $0.992(0.983-1.002)$ & 0.100 & & \\
\hline \multirow[t]{2}{*}{ Working pattern } & Night shift & $1.093(0.644-1.857)$ & 0.741 & & \\
\hline & Split shift & $0.689(0.042-11.234)$ & 0.794 & & \\
\hline
\end{tabular}

${ }^{\mathrm{a} O R}$ calculated using logistic regression test, ${ }^{\mathrm{b}} \mathrm{Adjusted} \mathrm{OR}$ calculated using multiple logistic regression test $C l$ confidence interval; $D M$ diabetes mellitus; $B M I$ body mass index; $O R$ odd ratio 
statistically significant. Regarding oral antidiabetic agent, researchers have suggested that metformin therapy lowers cancer risk, while sulfonylureas increase carcinogenesis risk [28-30]. Herein, use of antidiabetic drugs increased cervical cancer risk. Because these data did not include which diabetic drugs were used, it is difficult to either determine the effects of individual drugs or interpret these findings more generally. Moreover, because diabetic drugs are almost exclusively given to DM patients and those factors are highly correlated, the DM medication was excluded from the multiple logistic regression model.

BMI was positively associated with cervical cancer not only independently, but also after adjusting for other factors. Some researchers have also reported that obesity is weakly associated with an increased risk of cervical cancer [31]. One interesting study showed that obese women are at increased risk of having inappropriate cervical cancer screenings before cancer diagnosis, possibly due to a negative body image, bias on the part of health care providers, poor health behaviors, and comorbidities affecting regular care [32].

No notable results were found regarding work hours and schedule. Few studies have explored the potential associations between night shift work and cancer risk, reporting lack of evidence or few correlations [33, 34]. Since our data were cross-sectional, it is difficult to suggest causal relations. For example, women who were diagnosed with cervical cancer may have reduced their work hours or moved to a shift that carried fewer burdens. Further prospective studies are needed to assess a broad range of occupations and various socioeconomic characteristics.

A major strength of this study is that it was based on extensive nationwide survey data, including 29,557 women in Korea. Furthermore, relatively recent data (2010-2018) were used, reflecting current disease patterns and trends. There are also several limitations. The study was cross-sectional; thus, exposure and outcomes were assessed simultaneously and deductions about interrelated courses are difficult. Finally, most of these data were derived from self-report questionnaires based on participant recall.

\section{Conclusion}

Several factors, including passive cigarette smoking at home, diabetes, and high BMI, are related to increased risk of cervical cancer among women in South Korea.

\section{Abbreviations}

BMI: Body mass index; OR: Odds ratio; Cl: Confidence intervals; HPV: Human papilloma virus; DM: Diabetes mellitus; KNHANES: Korea National Health and Nutrition Examination Survey; CIN: Cervical intraepithelial neoplasm

\section{Acknowledgements}

None.

\section{Authors' contributions}

All authors contributed to the study design and execution. JY, HN collected the data and wrote the manuscript. DW, MJ, and JE analyzed the data. YJ reviewed the data and wrote manuscript. All authors have read and approved the final manuscript.

\section{Funding}

None.

Availability of data and materials

The datasets analyzed during the current study are available in website of The Korea Disease Control and Prevention Agency; Korea National Health and Nutrition Examination Survey repository, [https://knhanes.cdc.go.kr/ knhanes/sub03/sub03_02_05.do].

\section{Declarations}

Ethics approval and consent to participate

Written informed consent was acquired from all participants before the survey was administered. Institutional Review Board of the Catholic University of Korea, Bucheon, Republic of Korea approved this study (HC20ZASI0107). All methods were performed in accordance with the relevant guidelines and regulations.

\section{Consent for publication}

Not applicable.

\section{Competing interests}

None.

Received: 12 January 2021 Accepted: 17 June 2021

Published online: 31 July 2021

\section{References}

1. International Agency for Research on Cancer. Estimated age-standardized incidence and mortality rates (World) in 2020, females, all ages. 2020. https://gco.iarc.fr/today/online-analysis-dual-bars-2?v=2020\&mode=ca ncer\&mode_population=regions\&population $=410 \&$ populations $=410 \&$ key $=$ asr\&sex $=2 \&$ cancer $=39 \&$ type $=0 \&$ statistic $=5 \&$ prevalence $=0 \&$ population group $=0 \&$ ages_group $\% 5 \mathrm{~B} \% 5 \mathrm{D}=0$ \&ages_group $\% 5 \mathrm{~B} \% 5 \mathrm{D}=17 \& \mathrm{nb}$ _items $=$ 10\&group_cancer $=1$ \&include_nmsc $=1$ \&include_nmsc_other $=1$ \&dual_ distribution $=1 \&$ population $1=410 \&$ population $2=900 \&$ show_values $=\mathrm{fa}$ Ise\&type_multiple=\%257B\%2522inc\%2522\%253Atrue\%252C\%2522mort\%2 522\%253Atrue\%252C\%2522prev\%2522\%253Afalse\%257D\&population group_globocan_id=8type_sort=0\#collapse-group-0-3 Accessed 22 Dec 2020.

2. Crosbie EJ, Einstein MH, Franceschi S, Kitchener HC. Human papillomavirus and cervical cancer. Lancet. 2013;382(9895):889-99. https://doi.org/10.1016/ S0140-6736(13)60022-7.

3. Anderson DM, Lee J, Elkas JC. Cervical and vaginal cancer. In: Berek JS, editor. Berek and Novak's gynecology. Philadelphia: Wolters Kluwer; 2020. p. 1038-76.

4. Roura E, Castellsaque X, Pawlita M, Travier N, Waterboer T, Margall N, et al. Smoking as a major risk factor for cervical cancer and pre-cancer: results from the EPIC cohort. Int J Cancer. 2014;135(2):453-66. https://doi.org/10.1 002/ijc.28666.

5. Su B, Qin W, Xue F, Wei X, Guan Q, Jiang W, et al. The relation of passive smoking with cervical cancer: a systematic review and meta-analysis. Medicine (Baltimore). 2018;97(46):e13061. https://doi.org/10.1097/MD. 0000000000013061.

6. Louie KS, Castellsague X, de Sanjose S, Herrero R, Meijer CJ, Shah K, et al. Smoking and passive smoking in cervical cancer risk: pooled analysis of couples from the IARC multicentric case-control studies. Cancer Epidemiol Biomark Prev. 2011;20(7):1379-90. https://doi.org/10.1158/1055-9965.EPI-110284 .

7. Vrachnis N, lavazzo C, lliodromiti Z, Sifakis S, Alexandrou A, Siristatidis C, et al. Diabetes mellitus and gynecologic cancer: molecular mechanisms, 
epidemiological, clinical and prognostic perspectives. Arch Gynecol Obstet. 2016;293(2):239-46. https://doi.org/10.1007/s00404-015-3858-z.

8. Friberg E, Orsini N, Mantzoros CS, Wolk A. Diabetes mellitus and risk of endometrial cancer: a meta-analysis. Diabetologia. 2007;50(7):1365-74. https://doi.org/10.1007/s00125-007-0681-5.

9. Keum N, Greenwood DC, Lee DH, Kim R, Aune D, Ju W, et al. Adult weight gain and adiposity-related cancers: a dose-response meta-analysis of prospective observational studies. J Natl Cancer Inst. 2015;107(2):djv088.

10. Arnold M, Jiang L, Stefanick ML, Johnson KC, Lane DS, LeBlanc ES, et al. Duration of adulthood overweight, obesity, and Cancer risk in the Women's Health Initiative: a longitudinal study from the United States. PLoS Med. 2016;13(8):e1002081. https://doi.org/10.1371/journal.pmed.1002081.

11. Cohen PA, Jhingran A, Oaknin A, Denny L. Cervical cancer. Lancet. 2019; 393(10167):169-82. https://doi.org/10.1016/S0140-6736(18)32470-X.

12. Lee M, Park EC, Chang HS, Kwon JA, Yoo KB, Kim TH. Socioeconomic disparity in cervical cancer screening among Korean women: 1998-2010. BMC Public Health. 2013;13(1):553. https://doi.org/10.1186/1471-2458-13553.

13. Choi E, Lee YY, Suh M, Lee EY, Mai TTX, Ki M, et al. Socioeconomic inequalities in cervical and breast Cancer screening among women in Korea, 2005-2015. Yonsei Med J. 2018;59(9):1026-33. https://doi.org/10.3349/ ymj.2018.59.9.1026

14. Lee HE, Zaitsu M, Kim EA, Kawachi I. Cancer incidence by occupation in Korea: longitudinal analysis of a Nationwide cohort. Saf Health Work. 2020; 11(1):41-9. https://doi.org/10.1016/j.shaw.2019.12.004.

15. The Korea Disease Control and Prevention Agency. Korea National Health and Nutrition Examination Survey. 2020. https://knhanes.cdc.go.kr/knhanes/ sub01/sub01_02.do Accessed 22 Dec 2020.

16. Zeng XT, Xiong PA, Wang F, Li CY, Yao J, Guo Y. Passive smoking and cervical cancer risk: a meta-analysis based on 3,230 cases and 2,982 controls. Asian Pac J Cancer Prev. 2012;13(6):2687-93. https://doi.org/10.7314/APJCP.2 012.13.6.2687.

17. Trimble CL, Genkinger JM, Burke AE, Hoffman SC, Helzlsouer KJ, Diener-West $\mathrm{M}$, et al. Active and passive cigarette smoking and the risk of cervical neoplasia. Obstet Gynecol. 2005;105(1):174-81. https://doi.org/10.1097/01.A OG.0000148268.43584.03.

18. Kim AS, Ko HJ, Kwon JH, Lee JM. Exposure to Secondhand Smoke and Risk of Cancer in Never Smokers: a Meta-Analysis of Epidemiologic Studies. Int J Environ Res Public Health. 2018;15(9):1981.

19. Ward KK, Berenson AB, Breitkopf CR. Passive smoke exposure and abnormal cervical cytology in a predominantly Hispanic population. Am J Obstet Gynecol. 2011;204(3):213 e1-6.

20. Tsai HT, Tsai YM, Yang SF, Wu KY, Chuang HY, Wu TN, et al. Lifetime cigarette smoke and second-hand smoke and cervical intraepithelial neoplasm--a community-based case-control study. Gynecol Oncol. 2007; 105(1):181-8. https://doi.org/10.1016/j.ygyno.2006.11.012.

21. Tay SK, Tay KJ. Passive cigarette smoking is a risk factor in cervical neoplasia. Gynecol Oncol. 2004;93(1):116-20. https://doi.org/10.1016/j.ygyno.2003.12. 032.

22. Min KJ, Lee JK, So KA, Kim MK. Association between passive smoking and the risk of cervical intraepithelial Neoplasia 1 in Korean women. J Epidemiol. 2018;28(1):48-53. https://doi.org/10.2188/jea.JE20160118.

23. Coker AL, Bond SM, Williams A, Gerasimova T, Pirisi L. Active and passive smoking, high-risk human papillomaviruses and cervical neoplasia. Cancer Detect Prev. 2002;26(2):121-8. https://doi.org/10.1016/S0361-090X(02)000399.

24. Ranc K, Jørgensen ME, Friis S, Carstensen B. Mortality after cancer among patients with diabetes mellitus: effect of diabetes duration and treatment. Diabetologia. 2014;57(5):927-34. https://doi.org/10.1007/s00125-014-3186-z.

25. Chen S, Tao M, Zhao L, Zhang X. The association between diabetes/ hyperglycemia and the prognosis of cervical cancer patients: a systematic review and meta-analysis. Medicine (Baltimore). 2017;96(40):e7981. https:// doi.org/10.1097/MD.0000000000007981.

26. Barone BB, Yeh HC, Snyder CF, Peairs KS, Stein KB, Derr RL, et al. Long-term all-cause mortality in cancer patients with preexisting diabetes mellitus: a systematic review and meta-analysis. JAMA. 2008;300(23):2754-64. https:// doi.org/10.1001/jama.2008.824.

27. Wojciechowska J, Krajewski W, Bolanowski M, Krecicki T, Zatonski T. Diabetes and Cancer: a review of current knowledge. Exp Clin Endocrinol Diabetes. 2016;124(5):263-75. https://doi.org/10.1055/s-0042-100910.
28. Chang CH, Lin JW, Wu LC, Lai MS, Chuang LM. Oral insulin secretagogues, insulin, and cancer risk in type 2 diabetes mellitus. J Clin Endocrinol Metab. 2012;97(7):E1170-5. https://doi.org/10.1210/jc.2012-1162.

29. Evans JM, Donnelly LA, Emslie-Smith AM, Alessi DR, Morris AD. Metformin and reduced risk of cancer in diabetic patients. BMJ. 2005;330(7503):1304-5. https://doi.org/10.1136/bmj.38415.708634.F7.

30. Currie CJ, Poole CD, Gale EA. The influence of glucose-lowering therapies on cancer risk in type 2 diabetes. Diabetologia. 2009;52(9):1766-77. https:// doi.org/10.1007/s00125-009-1440-6.

31. Poorolajal J, Jenabi E. The association between BMI and cervical cancer risk: a meta-analysis. Eur J Cancer Prev. 2016;25(3):232-8. https://doi.org/10.1097/ CEJ.0000000000000164.

32. Gnade CM, Hill EK, Botkin HE, Hefel AR, Hansen HE, Sheets KA, et al. Effect of obesity on cervical Cancer screening and outcomes. J Low Genit Tract Dis. 2020;24(4):358-62. https://doi.org/10.1097/LGT.0000000000000570.

33. Travis RC, Balkwill A, Fensom GK, Appleby PN, Reeves GK, Wang XS, et al. Night Shift Work and Breast Cancer Incidence: Three Prospective Studies and Meta-analysis of Published Studies. J Natl Cancer Inst. 2016;108(12): djw169.

34. Schwarz C, Pedraza-Flechas AM, Lope V, Pastor-Barriuso R, Pollan M, PerezGomez B. Gynaecological cancer and night shift work: a systematic review. Maturitas. 2018;110:21-8. https://doi.org/10.1016/j.maturitas.2018.01.008.

\section{Publisher's Note}

Springer Nature remains neutral with regard to jurisdictional claims in published maps and institutional affiliations.
Ready to submit your research? Choose BMC and benefit from:

- fast, convenient online submission

- thorough peer review by experienced researchers in your field

- rapid publication on acceptance

- support for research data, including large and complex data types

- gold Open Access which fosters wider collaboration and increased citations

- maximum visibility for your research: over $100 \mathrm{M}$ website views per year

At BMC, research is always in progress.

Learn more biomedcentral.com/submissions 